\title{
Metformin-treated patients with type 2 diabetes have normal mitochondrial complex I respiration
}

\author{
S. Larsen • R. Rabøl • C. N. Hansen • S. Madsbad • \\ J. W. Helge $\cdot$ F. Dela
}

Received: 18 July 2011 / Accepted: 22 September 2011 / Published online: 19 October 2011

(C) Springer-Verlag 2011

\begin{abstract}
Aims/hypothesis The glucose-lowering drug metformin has been shown to inhibit complex I of the mitochondrial electron transport chain in skeletal muscle. To investigate this effect in vivo we studied skeletal muscle mitochondrial respiratory capacity and content from patients with type 2 diabetes treated with metformin $(n=14)$ or sulfonylurea $(n=$ $8)$ and healthy control $(n=18)$ participants.

Methods Mitochondrial respiratory capacity was measured ex vivo in permeabilised muscle fibres obtained from the vastus lateralis muscle of all participants. The respiratory response to in vitro titration with metformin was measured in controls. Citrate synthase (CS) activity, and fasting plasma glucose, insulin and $\mathrm{HbA}_{1 \mathrm{c}}$ levels were measured and body composition was determined.

Results Participants were matched for age, BMI and percentage body fat. Fasting plasma glucose concentrations were higher $(p<0.05)$ in those treated with sulfonylureas and metformin than in controls. CS activity was comparable between metformin-treated and control participants, but tended to be lower in those receiving sulfonylureas. Mitochondrial respiratory capacity with substrates for complex I and complex I and II was comparable in the groups, both when estimated per mg of tissue and when
\end{abstract}

S. Larsen $(\bowtie) \cdot$ R. Rabøl $\cdot$ C. N. Hansen $\cdot$ J. W. Helge $\cdot$ F. Dela

Xlab, Center for Healthy Aging,

Department of Biomedical Sciences, Faculty of Health Sciences,

University of Copenhagen,

Blegdamsvej 3b,

2200 Copenhagen N, Denmark

e-mail: stelar@sund.ku.dk

S. Madsbad

Department of Endocrinology, Hvidovre University Hospital, University of Copenhagen,

Copenhagen, Denmark normalised to CS activity. In vitro metformin titration demonstrated a dose-dependent inhibitory effect on complex I and II in human skeletal muscle at suprapharmacological concentrations.

Conclusions/interpretation Metformin treatment does not inhibit mitochondrial complex I respiration in the electron transport chain in human skeletal muscle of patients with type 2 diabetes when measured ex vivo. Inhibition of complex I and II respiration in controls was demonstrated by metformin titration in vitro at doses well above those observed during metformin treatment.

Keywords Complex I - Metformin · Mitochondrial function. Type 2 diabetes

\begin{tabular}{|c|c|}
\hline \multicolumn{2}{|c|}{ Abbreviations } \\
\hline AMPK & $\begin{array}{l}\text { Adenosine monophosphate-activated protein } \\
\text { kinase }\end{array}$ \\
\hline CS & Citrate synthase \\
\hline mtDNA & Mitochondrial DNA \\
\hline PGC- $1 \alpha$ & $\begin{array}{l}\text { Peroxisome proliferator-activated receptor- } \gamma \\
\text { coactivator- } 1 \alpha\end{array}$ \\
\hline $\mathrm{RCR}$ & Respiratory control ratio \\
\hline SCR & Substrate control ratio \\
\hline
\end{tabular}

\section{Introduction}

The biguanide metformin is the most commonly recommended drug used in the treatment of type 2 diabetes. The exact mechanism of action is unknown, but a decrease in hepatic glucose production [1] and an increase in glucose disposal in skeletal muscle [2] contribute to the glucose- 
lowering effect. The hypoglycaemic effect is reached without stimulation of insulin secretion. Whether the reduced hepatic glucose production is due to reduced rates of gluconeogenesis [1] or reduced rates of hepatic glycogenolysis [3] is still controversial. In addition to these beneficial effects on glycaemic control, metformin also improves the lipid profile and reduces cardiovascular risk $[4,5]$. In contrast, the glucose-lowering effect of sulfonylureas is mediated via activation of the insulin-producing beta cells [6], and these drugs have no direct effect on liver or skeletal muscle.

Adenosine monophosphate-activated protein kinase (AMPK) is a major regulator of lipid and glucose metabolism [7] and has been suggested as a possible molecular target of metformin. Metformin increases the activation of AMPK both in vivo and in vitro $[2,7]$. Metformin possibly enhances peroxisome proliferator-activated receptor- $\gamma$ coactivator- $1 \alpha$ (PGC-1 $\alpha$ ) levels and mitochondrial biogenesis via AMPK phosphorylation in skeletal muscles [8]. Metformin treatment has also been associated with inhibition of complex I in the mitochondrial electron transport chain in studies of rat muscle or liver and in studies using cell lines [9-12]. A recent study on rat skeletal muscle suggested that a possible inhibitory effect of metformin on mitochondrial respiration was concentration-dependent [13] with no effect of metfor$\min$ in concentrations up to $1.0 \mathrm{mmol} / \mathrm{l}$ in the vicinity of the mitochondria. A therapeutic dose of metformin in humans of $1,000 \mathrm{mg}$ elicits a plasma metformin concentration of approximately $0.1 \mathrm{mmol} / 1[14,15]$. The peak metformin concentration in skeletal muscle (mitochondria) is lower than the plasma level [16]. The metformin concentration is of importance and concentrations above $0.5-1.0 \mathrm{mmol} / \mathrm{l}$ in the mitochondria might not be clinically relevant $[9,13,17]$.

The present study was undertaken to examine if therapeutic doses of metformin inhibit complex I in the mitochondrial respiratory chain ex vivo in human skeletal muscle from patients with type 2 diabetes and healthy control participants, and to investigate the acute doseresponse relationship between metformin and skeletal muscle complex I and II respiration in healthy control participants. To our knowledge this has not been investigated in human skeletal muscle before. Given the large number of patients treated with metformin and the increasing research focus on mitochondrial respiration in insulin resistance, it is important to resolve whether patients receiving metformin treatment should be excluded from such studies. Simple discontinuation of the metformin treatment prior to the examination is not an option because the elimination half-life in blood is long $(\sim 18 \mathrm{~h})$. Thus, discontinuation would have to be lengthy, with major metabolic derangement as a consequence. We hypothesised that there would be no inhibitory effect on mitochondrial complex I respiration in skeletal muscle from patients treated with therapeutic doses of metformin $(1,000$ $2,000 \mathrm{mg} /$ day), but that inhibition of complex I could be seen with in vitro use of supratherapeutic concentrations of metformin.

\section{Methods}

Forty participants were included in the study: 22 patients with type 2 diabetes and 18 age-matched control participants (all men). Participant characteristics are given in Table 1. The patients with type 2 diabetes were either treated with metformin (dose: $2,000 \pm 200 \mathrm{mg} /$ day, $n=14$ ) or sulfonylurea (glimepiride, $2.4 \pm 0.2 \mathrm{mg} /$ day, $n=8$ ). Diabetes duration is listed in Table 1. All control participants had normal glucose tolerance (fasting plasma glucose $<6.0 \mathrm{mmol} / 1$ and $\mathrm{HbA}_{1 \mathrm{c}}$ $<6.0 \%$ [ $42 \mathrm{mmol} / \mathrm{mol}]$ ). A list of concomitant medications for all participants is provided in Table 2.

On the study day, participants arrived at the laboratory after an overnight fast $(12 \mathrm{~h})$. They were instructed to abstain from alcohol and strenuous exercise for the day before the study, and not to take their usual medication on the morning of the study, meaning that the last administration of medication was $12 \mathrm{~h}$ before the biopsy was obtained. This approach was used because we wanted to investigate the chronic rather than the acute effect of metformin. An acute effect of metformin was investigated in additional titration experiments. A medical history was taken and physical examination performed, including a measurement of body composition by dual-energy X-ray absorptiometry scan (Lunar Prodigy Advance; Lunar, Madison, WI, USA). A muscle biopsy was obtained from

Table 1 Participants' characteristics

\begin{tabular}{|c|c|c|c|}
\hline Characteristic & $\begin{array}{l}\text { Metformin } \\
(n=14)\end{array}$ & $\begin{array}{l}\text { Sulfonylurea } \\
(n=8)\end{array}$ & $\begin{array}{l}\text { Controls } \\
(n=18)\end{array}$ \\
\hline Age (years) & $54 \pm 3$ & $61 \pm 2$ & $55 \pm 2$ \\
\hline Weight (kg) & $100 \pm 3$ & $90 \pm 5$ & $99 \pm 3$ \\
\hline BMI $\left(\mathrm{kg} / \mathrm{m}^{2}\right)$ & $30 \pm 1$ & $30 \pm 1$ & $30 \pm 1$ \\
\hline Fat $(\%)$ & $30 \pm 1$ & $33 \pm 2$ & $31 \pm 1$ \\
\hline $\begin{array}{l}\text { Time since diagnosis } \\
\text { (years) }\end{array}$ & $6 \pm 1$ & $4 \pm 1$ & - \\
\hline $\mathrm{HbA}_{1 \mathrm{c}}(\%)$ & $7.8 \pm 0.5^{*}$ & $6.6 \pm 0.2 *$ & $5.4 \pm 0.1$ \\
\hline $\mathrm{HbA}_{1 \mathrm{c}}(\mathrm{mmol} / \mathrm{mol})$ & $62 \pm 5^{*}$ & $49 \pm 2 *$ & $36 \pm 1$ \\
\hline $\begin{array}{l}\text { Fasting blood glucose } \\
(\mathrm{mmol} / \mathrm{l})\end{array}$ & $9.5 \pm 0.9 *$ & $7.9 \pm 0.3 *$ & $5.4 \pm 0.1$ \\
\hline $\begin{array}{l}\text { Fasting insulin } \\
(\mathrm{pmol} / \mathrm{l})\end{array}$ & $64 \pm 9$ & $67 \pm 18$ & $51 \pm 5$ \\
\hline QUICKI index & $0.32 \pm 0.01 *$ & $0.33 \pm 0.01^{*}$ & $0.36 \pm 0.01$ \\
\hline NEFA $(\mu \mathrm{mol} / 1)$ & $541 \pm 43$ & $414 \pm 74$ & $476 \pm 54$ \\
\hline
\end{tabular}

Data are means $\pm \mathrm{SE}$

${ }^{*} p<0.05$ compared with control participants 
Table 2 Number of participants taking medications

\begin{tabular}{llll}
\hline Medication & $\begin{array}{l}\text { Metformin } \\
(n=14)\end{array}$ & $\begin{array}{l}\text { Sulfonylurea } \\
(n=8)\end{array}$ & $\begin{array}{l}\text { Controls } \\
(n=18)\end{array}$ \\
\hline ACE inhibitor & 5 & 2 & - \\
Statin & 8 & 5 & - \\
$\mathrm{Ca}^{2+}$ antagonist & 1 & 1 & - \\
Aspirin & 3 & 3 & 1 \\
ARB & 1 & 1 & - \\
\hline
\end{tabular}

$\mathrm{ARB}$, angiotensin receptor blocker

the vastus lateralis using the Bergstrom method and a blood sample was taken.

The ethics committee of the municipality of Copenhagen and Frederiksberg in Denmark approved the study protocol (file number H-KF-320893), and oral and written consent were obtained from each participant in accordance with the Helsinki declaration.

Analytical procedures The muscle biopsy was divided into two parts. One part was prepared for respirometric measurements. The other part of the biopsy was snap frozen in liquid nitrogen within $15 \mathrm{~s}$ of sampling and stored at $-80^{\circ} \mathrm{C}$ until further analysis.

Citrate synthase (CS) activity was measured as described by Andersen et al. [18]. Quantification of genomic and mitochondrial DNA (mtDNA) was measured as described by Kraunsoe et al. [19]

Blood samples were collected in chilled tubes and immediately centrifuged for $10 \mathrm{~min}\left(2,500 \mathrm{~g} ; 4^{\circ} \mathrm{C}\right)$. The plasma fraction was collected and stored at $-20^{\circ} \mathrm{C}$ or $-80^{\circ} \mathrm{C}$ prior to analysis. Plasma glucose concentration was measured on an automated glucose analyser (ABL 800 flex; Radiometer, Copenhagen, Denmark). $\mathrm{HbA}_{1 \mathrm{c}}$ was analysed on a Bayer DCA 2000+ (Bayer Healthcare, Elkhart, IN, USA) using a latex immunoagglutination inhibition method. Plasma insulin concentrations were determined using a commercial ELISA kit (Dako, Glostrup, Denmark). Plasma NEFA concentration was measured using a Wako NEFA-C test kit (Wako Chemical, Neuss, Germany).

Preparation of permeabilised fibres for respirometry The procedure was carried out as described by Boushel et al. [20]. Briefly, muscle fibres were dissected free of blood and connective tissue using sharp forceps. After manual dissection, fibres were placed in ice-cold relaxing buffer (BIOPS) for $30 \mathrm{~min}$. The buffer contained: $\mathrm{CaK}_{2} \mathrm{EGTA} 2.77 \mathrm{mmol} / \mathrm{l}$, $\mathrm{K}_{2}$ EGTA $7.23 \mathrm{mmol} / \mathrm{l}, \mathrm{Na}_{2}$ ATP $5.77 \mathrm{mmol} / \mathrm{l}, \mathrm{MgCl}_{2} \cdot 6 \mathrm{H}_{2} \mathrm{O}$ $6.56 \mathrm{mmol} / \mathrm{l}$, taurine $20 \mathrm{mmol} / \mathrm{l}, \mathrm{Na}_{2}$ phosphocreatine $15 \mathrm{mmol} / \mathrm{l}$, imidazole $20 \mathrm{mmol} / \mathrm{l}$, dithiothreitol $0.5 \mathrm{mmol} / \mathrm{l}$, and 4-morpholineethanesulfonic acid $50 \mathrm{mmol} / 1$ at $\mathrm{pH} 7.1$. Saponin $(50 \mu \mathrm{g} / \mathrm{ml})$ was added to the BIOPS buffer. The fibres were then washed in ice-cold respiration media (MiR05) for $20 \mathrm{~min}$. Respiration media contained: EGTA $0.5 \mathrm{mmol} / \mathrm{l}$, $\mathrm{MgCl}_{2} \cdot 6 \mathrm{H}_{2} \mathrm{O} 3.0 \mathrm{mmol} / \mathrm{l}$, K-lactobionate $60 \mathrm{mmol} / \mathrm{l}$, taurine $20 \mathrm{mmol} / \mathrm{l}, \mathrm{KH}_{2} \mathrm{PO}_{4} 10 \mathrm{mmol} / \mathrm{l}$, HEPES $20 \mathrm{mmol} / \mathrm{l}$, sucrose $110 \mathrm{mmol} / \mathrm{l}$, and BSA $1 \mathrm{~g} / \mathrm{l}$ at $\mathrm{pH}$ 7.1. Finally, the muscle fibres were weighed and transferred to a high-resolution respirometer (Oxygraph-2 k; Oroboros, Innsbruck, Austria) for the final analysis.

Mitochondrial respiration protocol All substrate protocols were carried out in duplicate. Following routine respiration of the muscle fibres, malate $\left(\mathrm{M}_{2} ; 2 \mathrm{mmol} / \mathrm{l}\right)$ and glutamate $\left(\mathrm{GM}_{2}\right.$; $10 \mathrm{mmol} / \mathrm{l}$ ) were added, providing electrons to complex I (state $2)$; subsequently $\operatorname{ADP}\left(\mathrm{GM}_{3} ; 5 \mathrm{mmol} / \mathrm{l}\right)$ was added to assess state 3 respiration. Succinate was then added $\left(\mathrm{GMS}_{3} ; 10 \mathrm{mmol} / \mathrm{l}\right)$ to provide electrons for complex II, resulting in dual input into complex I and II. Finally cytochrome $c(10 \mu \mathrm{mol} / \mathrm{l})$ was added to control for outer mitochondrial membrane integrity.

Metformin titration To evaluate the acute metformin doseresponse effect on mitochondrial respiration, skeletal muscle from four of the healthy control participants was studied. Two different approaches were applied (incubation and titration). After the muscle fibres were permeabilised in saponin, as described earlier in this section, they were washed in MiR05 buffer containing different metformin concentrations $(0.1,1.0$, 10.0 and $30.0 \mathrm{mmol} / \mathrm{l}$ ) for $20 \mathrm{~min}$. The protocol for the incubation experiment was as follows: malate $(2 \mathrm{mmol} / \mathrm{l})$, glutamate $(10 \mathrm{mmol} / \mathrm{l}), \mathrm{ADP}(5 \mathrm{mmol} / \mathrm{l})$. The muscle fibres were prepared and placed in the respirometer as described earlier. For the titration experiment the following protocols were applied: (1) for assessment of possible complex I inhibition, malate ( $2 \mathrm{mmol} / \mathrm{l})$, glutamate $(10 \mathrm{mmol} / \mathrm{l}), \mathrm{ADP}(5 \mathrm{mmol} / \mathrm{l})$ and titrated metformin $(0.1,0.5,1.0,3.0,5.0,10.0,20.0$ and $30.0 \mathrm{mmol} / \mathrm{l})$; (2) for assessment of possible complex II inhibition, malate ( $2 \mathrm{mmol} / \mathrm{l})$, glutamate $(10 \mathrm{mmol} / \mathrm{l})$, ADP $(5 \mathrm{mmol} / \mathrm{l})$, rotenone $(0.5 \mu \mathrm{mol} / \mathrm{l})$, succinate $(10 \mathrm{mmol} / \mathrm{l})$ and titrated metformin $(0.1$, 0.5, 1.0, 3.0, 5.0, 10.0, 20.0 and $30.0 \mathrm{mmol} / \mathrm{l})$. Metformin was purchased from STADA (STADA Arzneimittel, Bad Vilbel, Germany), pulverised and dissolved in $\mathrm{H}_{2} \mathrm{O}$.

Calculations The QUICKI index was calculated as described by Katz et al. [21].

Statistics Data are presented as means $\pm \mathrm{SE}$ in text and in all figures and tables. $p$ values less than 0.05 were considered significant. Statistical analysis of differences in oxygen flux between the studied groups was carried out with a two-way ANOVA for repeated measures. In the case of a significant main effect and interaction between the variables, the Holm-Sidak method was used for post hoc analysis. Differences between the three groups were evaluated with a one-way ANOVA. If the normality test failed, the data 

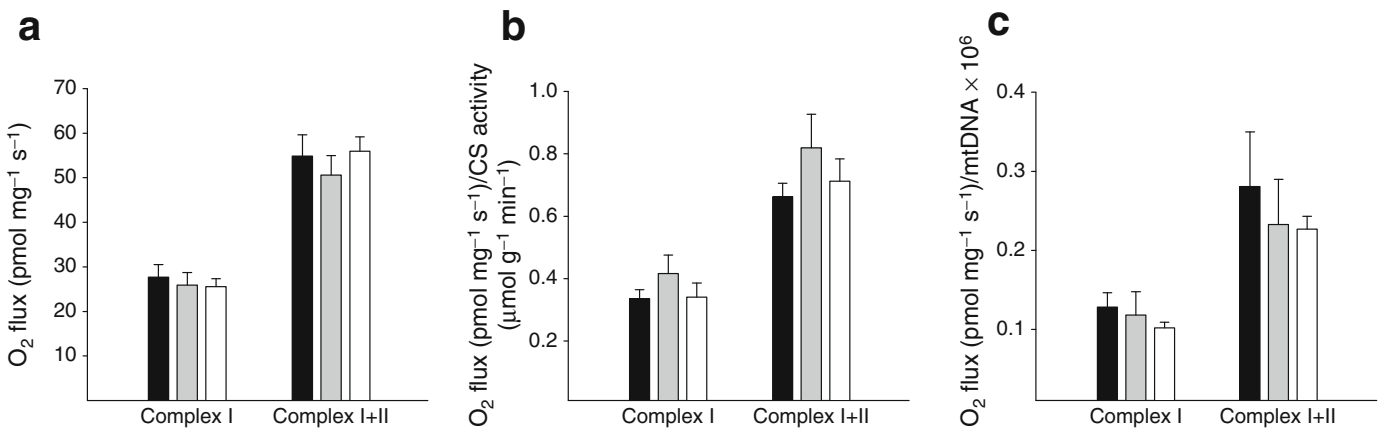

Fig. 1 Mitochondrial respiratory capacity was measured in permeabilised skeletal muscle biopsies from patients with type 2 diabetes treated with metformin $(n=14)$ or sulfonylurea $(n=8)$ and control participants $(n=18)$. a Mitochondrial respiratory capacity per $\mathrm{mg}$ tissue; $\mathbf{b}$ mitochondrial respiratory capacity normalised to CS activity; c mitochondrial respiratory capacity normalised to mtDNA content.

were $\log _{10}$ transformed and re-analysed. All statistical analysis was performed using the software program SigmaStat 3.1 (Systat Software, San Jose, CA, USA).

\section{Results}

Age, bodyweight, BMI and percentage body fat did not differ between the three groups (Table 1). Fasting plasma glucose and $\mathrm{HbA}_{1 \mathrm{c}}$ were significantly lower $(p<0.05)$ in control participants compared with both groups of patients with type 2 diabetes. Fasting insulin and NEFA concentration were similar between the groups. Insulin sensitivity (evaluated with the QUICKI index) was significantly lower $(p<0.05)$ in both treated groups compared with the control group. No difference was seen in the QUICKI index between the two groups of patients with type 2 diabetes. See Table 1 for characteristics of the participants.

Muscle characteristics CS activity tended to be lower in those taking sulfonylureas compared with those taking metformin $(p=0.059)$ and control participants $(p=0.078$; $66 \pm 6$ vs $83 \pm 5$ vs $87 \pm 7 \mu \mathrm{mol} \mathrm{g}^{-1} \mathrm{~min}^{-1}$, respectively). No difference was seen in CS activity between metformin and control participants. No difference was seen in mtDNA copies per mg tissue between metformin-treated, sulfonylurea-treated

Table 3 Substrate and RCRs

\begin{tabular}{llll}
\hline Ratio & Metformin $(n=14)$ & Sulfonylurea $(n=8)$ & Control $(n=18)$ \\
\hline RCR & $4.63 \pm 0.48$ & $5.13 \pm 0.63$ & $5.48 \pm 0.38$ \\
SCR & $0.51 \pm 0.03$ & $0.51 \pm 0.03$ & $0.47 \pm 0.03$ \\
\hline
\end{tabular}

$\mathrm{RCR}$, state $3 /$ state $2 ; \mathrm{SCR}, \mathrm{GM}_{3} / \mathrm{GMS}_{3}$
Complex I: malate, glutamate, ADP. Complex I and II: malate, glutamate, ADP, succinate. Data are means \pm SE. Patients with type 2 diabetes treated with metformin, black bars; patients with type 2 diabetes treated with sulfonylurea, grey bars; control participants, white bars
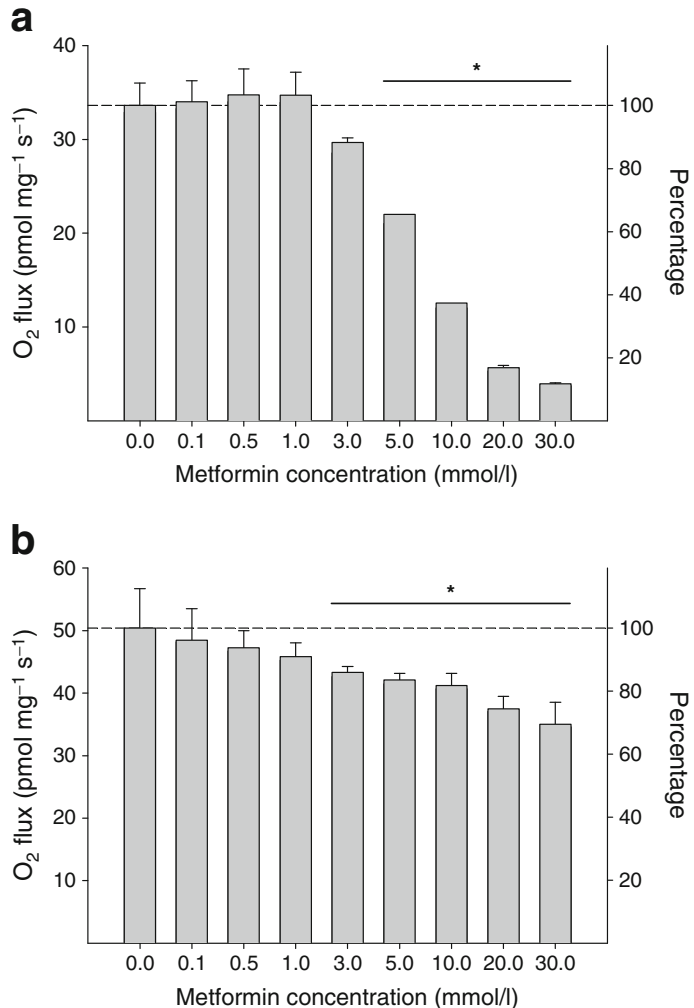

Fig. 2 Dose-dependent effects of metformin on mitochondrial respiratory capacity in skeletal muscle biopsies from healthy control participants. Metformin was titrated into the respirometer. The y-axes on the left correspond to respiratory flux rate $\left(\mathrm{pmol} \mathrm{mg}^{-1} \mathrm{~s}^{-1}\right)$; the $y$-axes on the right correspond to the percentage decrease from state 3 respiration with no metformin present $(0.0 \mathrm{mmol} / \mathrm{l})$. a Respiration with substrates for complex I with the addition of increasing doses of metformin. The concentration 0.0 refers to state 3 respiration with substrates for complex I (malate and glutamate). b Respiration with substrate for complex II with the addition of increasing doses of metformin. The concentration 0.0 refers to state 3 respiration with substrates for complex II (malate, glutamate, rotenone [inhibiting complex I] and succinate). Data are means \pm SE. ${ }^{*} p<0.05$ compared with state 3 respiration with no metformin ( 0.0 concentration) 
and control participants $(245 \pm 22$ vs $263 \pm 35$ vs $263 \pm 20$ mtDNA copies per $\mathrm{mg} \times 10^{6}$, respectively).

Mitochondrial respiration Maximal coupled mitochondrial respiratory capacity per mg tissue was similar in the groups, both with substrates for complex I and complex I and II (Fig. 1a). The same was seen when mitochondrial respiration was normalised to either CS activity (Fig. 1b) or mtDNA content (Fig. 1c). Substrate control ratio (SCR) for succinate $\left(\mathrm{GM}_{3} / \mathrm{GMS}_{3}\right)$ and respiratory control ratio (RCR) (state $3 /$ state 2 ) were not different between the three groups (Table 3).

Metformin titration Titration of metformin in the presence of substrates for complex I showed a decrease in respiration. This decrease, even though not statistically significant $(p=0.12)$, was first seen when the metformin concentration reached $3.0 \mathrm{mmol} / \mathrm{l}$; the magnitude of the decrease in respiration at this concentration was $12 \%$. Metformin concentrations higher than $3.0 \mathrm{mmol} / \mathrm{l}(5.0-30.0 \mathrm{mmol} / \mathrm{l})$ were accompanied by a significant decrease in state 3 respiration with complex I substrates. When the metformin concentration was $30.0 \mathrm{mmol} / \mathrm{l}$ in the respirometer chamber the magnitude of the decrease in respiration was $88 \%$ (Fig. 2a), which is similar to routine respiration without any substrates. When the muscle fibres were incubated in MiR05 and metformin at different concentrations, a similar decrease in mitochondrial respiration was seen as with the titration protocol (data not shown). When metformin was titrated into the respiratory chamber in the presence of an additional substrate for complex II respiration (succinate) a stepwise decrease in mitochondrial respiration was seen (Fig. 2b). At a metformin concentration of $3.0 \mathrm{mmol} / \mathrm{l}$ and higher the respiratory capacity was significantly different from state 3 respiration (complex I and II) without metformin present. No threshold in metformin concentration for a decrease in respiration with dual electron input to complex I and II seems to exist.

\section{Discussion}

The major finding in this study is that mitochondrial complex I respiration in skeletal muscle is not inhibited by normal pharmacological concentrations of metformin in patients with type 2 diabetes (dose 2,000 $\pm 200 \mathrm{mg} /$ day) compared with patients treated with sulfonylurea (glimepiride, $2.4 \pm 0.2 \mathrm{mg} /$ day) or control participants (Fig. 1a-c). An acute effect of metformin on mitochondrial respiration with substrates for complex I and II (Fig. 2a,b, respectively) was seen when metformin was added to permeabilised muscle fibres from healthy control participants. Further- more, a tendency was seen toward decreased CS activity in the sulfonylurea-treated patients compared with both the metformin-treated patients and the healthy control participants, with no difference between the metformin-treated patients and the healthy control participants. No difference was seen in mtDNA content per mg tissue between the three groups.

It is not clear where metformin has its primary effect, but different cellular targets (AMPK and complex I) have been outlined as possible targets for metformin [2, 7, 10, 11]. It has been speculated that increased AMPK phosphorylation could occur secondary to reduced ATP availability subsequent to inhibition of complex I $[2,10]$. It has been shown in skeletal muscle from rats that metformin increases PGC$1 \alpha$ protein levels, accompanied by increases in enzyme activity (CS and $\beta$-hydroxy-acyl-CoA-dehydrogenase activity). This could be mediated by an increased AMPK phosphorylation with subsequent stimulation of mitochondrial biogenesis [8]; an increase in AMPK phosphorylation by metformin has been shown in animal and human studies $[2,7,22]$. Thus, the difference in CS activity between the two patient groups in the present study may be due to a stimulatory chain effect of metformin [8].

Several studies have investigated the actions of metformin in the context of mitochondrial complex I inhibition in the electron transport chain. Studies on cells, animals and mitochondria isolated from human skeletal muscle samples have shown conflicting results [9-13]. Studies carried out on rat muscle (permeabilised fibres and isolated mitochondria) or liver or in cell lines may not be representative of skeletal muscle from human patients with type 2 diabetes. Recently, it has also been reported that fundamental differences exist in the respiratory responses of isolated mitochondria and permeabilised fibres [23].

A wide range of metformin concentrations have been used and data clearly show that complex I inhibition is concentration dependent. Metformin concentrations below $1.0 \mathrm{mmol} / \mathrm{l}$ have no inhibitory effect on complex I respiration in permeabilised skeletal muscle fibres or isolated liver mitochondria from rats $[9,13]$, which is in agreement with results from the present study in which patients with type 2 diabetes were treated with a clinically relevant dose of metformin. An important question is, therefore, what is the metformin concentration in the mitochondria of patients with type 2 diabetes. If the concentration is below $1.0 \mathrm{mmol} / \mathrm{l}$, then studies using metformin concentrations above this threshold are not clinically relevant. A metformin dose of $1,000 \mathrm{mg}$ (taken orally) has been calculated to elicit a metformin concentration in the mitochondria of approximately $0.1-0.5 \mathrm{mmol} / 1$ $[13,14,17]$. This estimate does not take the half-life of metformin (approximate $6.5 \mathrm{~h}$ in plasma and $18 \mathrm{~h}$ in blood) into consideration. So unless metformin accumulates in the 
mitochondria, previous studies using concentrations above $1.0 \mathrm{mmol} / \mathrm{l}$ are not physiologically relevant and the observed inhibitory effect may simply be due to a toxic effect of the drug.

An accumulation of metformin (at therapeutic doses) in the mitochondria from skeletal muscle is highly unlikely taking into consideration the fast first-pass metabolism, the high distribution volume and the low lipophilicity of the drug [24]. The low lipophilicity of the drug makes diffusion through cell membranes unlikely when pharmacological concentrations are used. It has been reported that there is no significant accumulation of metformin in plasma after the drug has been administered in multiple doses [24], and this finding can most likely be extended to skeletal muscle tissue [16]. Wilcock and Bailey reported practically no metformin accumulation in skeletal muscle from normal mice, and no metformin accumulation at all in mice with streptozotocin-induced diabetes [16]. It has previously been suggested that metformin accumulates in the mitochondria [25], and therefore it cannot be completely ruled out that an accumulation of metformin can occur in human skeletal muscle mitochondria.

The results from the present study support the notion that the inhibitory effect of metformin on complex I in human skeletal muscle is concentration dependent, and a clinical metformin dose $(2 \times 1,000 \mathrm{mg} /$ day $)$ has no inhibitory effect on complex I, which is an extension of the previous studies in animals $[9,13]$. It must be underlined that the present results only elucidate the effect of metformin on human skeletal muscle, and it is possible that an inhibitory effect may be seen in other tissues, for example the liver. In this context it should also be mentioned that metformin has an inhibitory effect on intact cells at lower concentrations compared with permeabilised cells $[9,11]$. This has to be investigated further in a patient population taking the drug at a pharmacological dose. It has previously been reported that metformin increases CS activity in rats [8]. In the present study we could not demonstrate a significantly higher CS activity in the metformin- vs the sulfonylureatreated patients, but a trend towards higher activity was observed $(p=0.059)$.

To investigate whether the metformin-induced inhibitory effect on complex I was dose-dependent, we incubated muscle fibres with different metformin concentrations and demonstrated, as many others have, that metformin has an inhibitory effect at high suprapharmacological concentrations $[9,13]$. When metformin is titrated directly into the respirometer chamber an inhibitory effect is seen at exactly the same concentrations as in the incubation studies. The titration regimen inhibits complex I respiration to the level of routine respiration (respiration without any substrates). In addition, we have also shown that metformin has an inhibitory effect on complex II in the electron transport chain. In these separate experiments, respiratory contribu- tion from complex I was avoided by the use of a specific inhibitor of complex I, rotenone. Thus, suprapharmacological metformin concentrations are not only inhibiting complex I, but also complex II in the electron transport chain. While the inhibition of complex I respiration is characterised by a threshold (Fig. 2a), the inhibitory effect of metformin on complex II seems to be gradual and continuous. Whether these findings are due to a timedependent decrease in mitochondrial respiration is highly unlikely. The curve for complex I respiration seems more like a dose-response curve in which a clear toxic effect of metformin is seen. Further studies are needed to characterise this observation.

In summary, we have found that a clinically relevant dose of metformin has no inhibitory effect on complex I respiration in human skeletal muscle, either when measured per $\mathrm{mg}$ of tissue or when normalised to mitochondrial content. Furthermore, we have shown that suprapharmacological metformin concentrations have an inhibitory effect on mitochondrial complex I and complex II respiration in skeletal muscle from healthy human participants.

Acknowledgements We thank the healthy participants and patients who volunteered to participate in this study. R. Kraunsøe and J. Bach are thanked for expert technical assistance. The financial support from the Nordea Foundation, the Novo Nordisk Foundation, the Kathrine and Vigo Skovgaards Foundation, the Aase and Ejnar Danielsens Foundation and the Danish Council for Independent ResearchMedical Sciences (271-07-0271) is gratefully acknowledged.

Contribution statement All authors (SL, RR, CNH, SM, JWH and FD) contributed substantially to: (1) the conception and design of the study, or the analysis and interpretation of data; (2) drafting the article or revising it critically for important intellectual content; and (3) final approval of the version to be published.

Duality of interest The authors declare that there is no duality of interest associated with this manuscript.

\section{References}

1. Stumvoll M, Nurjhan N, Perriello G, Dailey G, Gerich JE (1995) Metabolic effects of metformin in non-insulin-dependent diabetes mellitus. N Engl J Med 333:550-554

2. Musi N, Hirshman MF, Nygren J et al (2002) Metformin increases AMP-activated protein kinase activity in skeletal muscle of subjects with type 2 diabetes. Diabetes 51:2074-2081

3. Cusi K, Consoli A, Defronzo RA (1996) Metabolic effects of metformin on glucose and lactate metabolism in noninsulindependent diabetes mellitus. J Clin Endocrinol Metab 81:4059-4067

4. Kirpichnikov D, McFarlane SI, Sowers JR (2002) Metformin: an update. Ann Intern Med 137:25-33

5. Hundal RS, Krssak M, Dufour S et al (2000) Mechanism by which metformin reduces glucose production in type 2 diabetes. Diabetes 49:2063-2069

6. Groop LC (1992) Sulfonylureas in NIDDM. Diabetes Care 15:737-754 
7. Zhou G, Myers R, Li Y et al (2001) Role of AMP-activated protein kinase in mechanism of metformin action. J Clin Invest 108:1167-1174

8. Suwa M, Egashira T, Nakano H, Sasaki H, Kumagai S (2006) Metformin increases the PGC-1alpha protein and oxidative enzyme activities possibly via AMPK phosphorylation in skeletal muscle in vivo. J Appl Physiol 101:1685-1692

9. Brunmair B, Staniek K, Gras F et al (2004) Thiazolidinediones, like metformin, inhibit respiratory complex I: a common mechanism contributing to their antidiabetic actions? Diabetes 53:1052-1059

10. El-Mir MY, Nogueira V, Fontaine E, Averet N, Rigoulet M, Leverve X (2000) Dimethylbiguanide inhibits cell respiration via an indirect effect targeted on the respiratory chain complex I. J Biol Chem 275:223-228

11. Owen MR, Doran E, Halestrap AP (2000) Evidence that metformin exerts its anti-diabetic effects through inhibition of complex 1 of the mitochondrial respiratory chain. Biochem J 348:607-614

12. Carvalho C, Correia S, Santos MS, Seica R, Oliveira CR, Moreira PI (2008) Metformin promotes isolated rat liver mitochondria impairment. Mol Cell Biochem 308:75-83

13. Kane DA, Anderson EJ, Price JW III et al (2010) Metformin selectively attenuates mitochondrial $\mathrm{H}_{2} \mathrm{O}_{2}$ emission without affecting respiratory capacity in skeletal muscle of obese rats. Free Radic Biol Med 49:1082-1087

14. Scheen AJ (1996) Clinical pharmacokinetics of metformin. Clin Pharmacokinet 30:359-371

15. Bailey CJ, Turner RC (1996) Metformin. N Engl J Med 334:574-579

16. Wilcock C, Bailey CJ (1994) Accumulation of metformin by tissues of the normal and diabetic mouse. Xenobiotica 24:49-57
17. Bailey CJ (1992) Biguanides and NIDDM. Diabetes Care 15:755772

18. Andersen JL, Schjerling P, Andersen LL, Dela F (2003) Resistance training and insulin action in humans: effects of detraining. J Physiol 551:1049-1058

19. Kraunsoe R, Boushel R, Hansen CN et al (2010) Mitochondrial respiration in subcutaneous and visceral adipose tissue from patients with morbid obesity. J Physiol 588:2023-2032

20. Boushel R, Gnaiger E, Schjerling P, Skovbro M, Kraunsoe R, Dela F (2007) Patients with type 2 diabetes have normal mitochondrial function in skeletal muscle. Diabetologia 50:790-796

21. Katz A, Nambi SS, Mather K et al (2000) Quantitative insulin sensitivity check index: a simple, accurate method for assessing insulin sensitivity in humans. J Clin Endocrinol Metab 85:24022410

22. Fryer LG, Parbu-Patel A, Carling D (2002) The anti-diabetic drugs rosiglitazone and metformin stimulate AMP-activated protein kinase through distinct signaling pathways. J Biol Chem 277:25226-25232

23. Picard M, Taivassalo T, Ritchie D et al (2011) Mitochondrial structure and function are disrupted by standard isolation methods. PLoS One 6:e18317

24. Graham GG, Punt J, Arora M et al (2011) Clinical pharmacokinetics of metformin. Clin Pharmacokinet 50:81-98

25. Dykens JA, Jamieson J, Marroquin L, Nadanaciva S, Billis PA, Will Y (2008) Biguanide-induced mitochondrial dysfunction yields increased lactate production and cytotoxicity of aerobically-poised HepG2 cells and human hepatocytes in vitro. Toxicol Appl Pharmacol 233:203-210 